Community Transport meets Mobility as a Service: on the road to a new a flexible future

\title{
Community Transport meets Mobility as a Service: on the road to a new a flexible future
}

Corinne Mulley*a ${ }^{\star}$ John D Nelson $^{\mathrm{b}}$, Liz Reedy ${ }^{\mathrm{a}}$ and Steve Wright ${ }^{\mathrm{b}}$

a Institute of Transport and Logistics Studies (C13), The University of Sydney Business School, NSW 2006, Australia

${ }^{b}$ Centre for Transport Research, School of Engineering, University of Aberdeen, AB24 3UF, UK

* Corresponding author: Institute of Transport and Logistics Studies (H73), The University of Sydney Business School, NSW 2006, Australia +61 (0)2 9114 1842, corinne.mulley@sydney.edu.au

Keywords: Mobility as a Service; Service Package; Community Transport, Classification codes: L91; L98; H49; I38; J14

\begin{abstract}
The growth of ridesharing and other "new mobility services (NMS)" poses challenges for traditional public transport operators because they create an environment where consumers can demand an "integrated mobility" from different transport modes and improved accessibility (information, booking, payment systems etc). More recently the discussion about how to deliver "integrated mobility" has led to the emerging "Mobility as a Service (MaaS)" concept. MaaS is variously defined but the essential idea is to see transport or mobility not as a physical asset to purchase (e.g. a car) but as a single service available on demand and incorporating all transport services from cars to buses to rail and on-demand services.

The paper's principal consideration is on how MaaS is relevant to public transport. The idea of how MaaS might be used in the Community Transport (CT) sector provides a casestudy. The CT sector is unusual in providing mobility for a user group which typically does not see mobility as a physical asset to purchase. Following a review of relevant literature, the paper describes the outcome of a study with five Australian CT operators. A semistructured conversation followed by a discussion type meeting brought CEOs together to explore the concept of mobility as a service and the types of package that might be offered. Findings indicate a strong enthusiasm amongst CT operators for offering packages of mobility services to their current users and to investigate delivery of packages to nonusers/new users.
\end{abstract}

\section{Introduction}

Much of the literature on Mobility as a Service (MaaS) appears to focus on a changing role for the car. From a still limited literature, Mobility as a Service (MaaS) has no single definition. All definitions try to capture the essential idea which is to see transport or mobility as a single service available on demand and incorporating all transport services from cars to buses to rail rather than as a physical asset to purchase (e.g. a car) (Transport Systems 
Community Transport meets Mobility as a Service: on the road to a new a flexible future

Catapult 2015). In this paper we argue that it is important not to ignore the crucial role of public transport (both fixed route and flexible) in the delivery of MaaS. Using the Community Transport (CT) sector in Australia as a case study the paper describes a study to ascertain whether CT organisations have an appetite to become mobility providers. This is a timely investigation since the funding of CT is set to change providing a necessity for CT operators to reassess the way in which their services are provided. The proposed person-centred funding (PCF) change puts the eligible client in charge of the funds they receive to spend as they see fit, rather than the current regime where the subsidy is in the hands of the suppliers or CT organisation. This change strikes at the heart of the way in which CT is organised. MaaS however provides an opportunity to bundle services in such a way that the eligible client can benefit from a collection of services, probably very similar to their current "consumption", whilst opening up the service to non-eligible passengers as well. For CT operators it offers the opportunity to provide some cross-subsidy within their service provision, thus providing a wider variety of services than otherwise would be the case.

The paper is structured as follows. A review of relevant literature identifies the main principles and drivers associated with MaaS as a concept and outlines the gaps in knowledge that exist (e.g. relating to the benefits and the delivery of MaaS packages). Following this the methodology adopted (semi-structured conversations and a discussion type meeting with five of the more entrepreneurial CT operators in Australia) and results obtained are discussed. Findings indicate a strong enthusiasm amongst CT operators for offering packages or bundles of mobility to their current users and to investigate delivery of packages to non-users/new users although it was clear that some operators would need encouragement to step outside of their traditional means of service delivery.

\section{Literature context}

\subsection{What is Mobility as a Service (MaaS)?}

Mobility as a Service (MaaS) is a new approach to achieving collaboration and integration between transport providers and where a user (traveller) engages a single service provider to coordinate and facilitate their mobility needs (Hietanen 2014). The European Commission (2016) notes that a paradigm change in transportation is expected to take place through MaaS, when service providers offer travellers easy, flexible, reliable, price-worthy and environmentally sustainable everyday travel, including for example public transport, car-sharing, car leasing and road use, as well as more efficient goods shipping and delivery possibilities. Crucially, the Commission notes no quantifiable evidence exists yet on the costs and benefits of MaaS, as well as on its influence on travel patterns and behaviour of the end users and there are clearly challenges to this as a sustainable future (Mulley 2017).

According to the MaaS Alliance (https://maas-alliance.eu/), Mobility as a Service puts users, both travellers and goods, at the core of transport services, offering them tailor-made mobility solutions based on their individual needs. They characterise MaaS as comprising three principal characteristics:

- Transport on Demand. MaaS fulfils users' needs for mobility with a wide range of transport services for both travellers and goods, offering tailor-made transport on demand. A MaaS provider arranges the most suitable transport means, be it public transport, taxi or car rental, or even ride-, car- or bike-sharing. 
Community Transport meets Mobility as a Service: on the road to a new a flexible future

- A Subscription Service. Users have no need to buy travel tickets or sign up for separate transport accounts since a MaaS account provides the freedom to choose the mobility required, for an agreed period or pay-as-you-go subscription.

- Potential to create new markets. For transport providers MaaS can offer new sales channels, access to untapped customer demand, simplified user account and payment management, as well as richer data on travel demand patterns and dynamics.

Hietanen (2014) suggests that one way to think of MaaS is as a mobility distribution model in which a customer's major transportation needs are met over one interface and one service provider. Services are bundled in to a package - similar to mobile phone price-plan packages (see Fig 1). The vision is to see the whole transport sector as a co-operative, interconnected ecosystem (comprising the transport infrastructure, transportation services, transport information and payment services) providing services reflecting the needs of customers. In this new transport model the boundaries between different transport modes are blurred or disappear completely.

MaaS Global (https://maas.global/) is the Finnish MaaS concept. They define MaaS, as "a way of combining options from different transport providers into a single mobile service, removing the hassle of planning and one-off payments". MaaS Global envisages a future environment where MaaS could offer an alternative to owning a car with personalised bundles or packages which offer the best option for every journey (e.g. a taxi, public transport, a rental car or a bike share). MaaS solutions can also offer value added services like deliveries for groceries or restaurant meals. In June 2016 MaaS Global test launched Whim in Helsinki, an app giving people instant access to multiple kinds of transport, from car sharing to taxis, buses, trains and bike share. The app (https://whimapp.com) became openly available in the Helsinki Region in May 2017 and the company is actively preparing new experiments, including in Amsterdam and the West Midlands (UK). As yet there are no papers reporting the experience of either trial. 
Community Transport meets Mobility as a Service: on the road to a new a flexible future

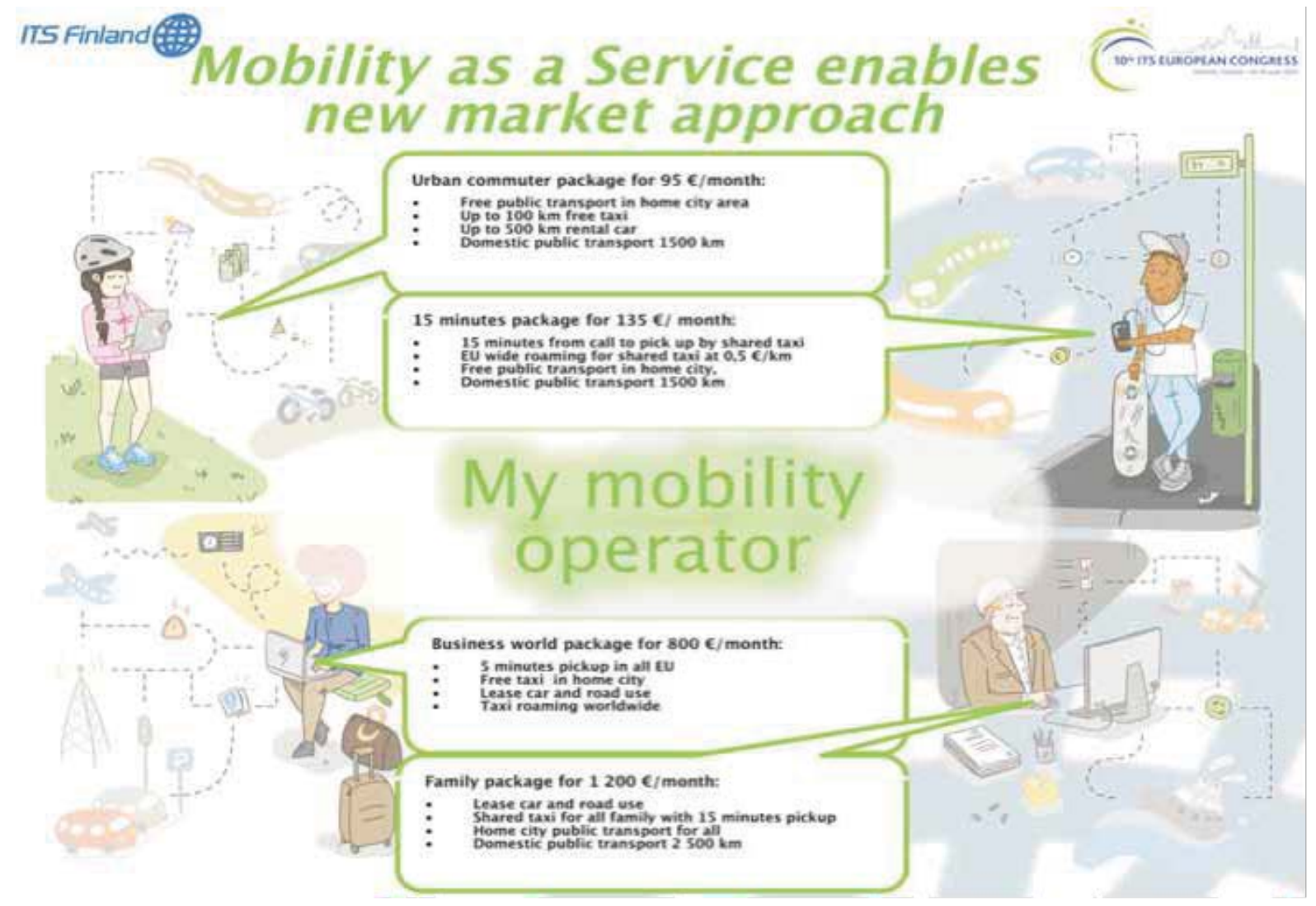

Source: Hietanen (2014)

Figure 1: An example of MaaS packages

Ubigo (http://www.ubigo.se/) is a MaaS project that has been trialled in Gothenburg. Ubigo is positioned as "a broker of everyday urban travel" and offers users one-stop access to a full range of collective mobility services (bicycle, public transport, car sharing, car rental, taxi). A relaunch for Stockholm is planned for later in 2017. Karlsson et al (2016) describe encouraging findings from the 6-month Ubigo trial in Gothenburg (2013/14) during which over 12000 transactions (public transport day tickets, car or taxi reservations) were made. Their evaluation indicated that the main obstacles to further dissemination of Maas may be found within and between service providing companies and organisations in terms of, e.g. regulations and institutional barriers. Other papers have described the field trial in more detail and outlined the challenges, particularly the challenge of integrating all aspects of mobility into a single service (Sochor et al 2016; Sochor et al 2015).

MaaS-London is a proposal for an integrated platform that includes registration and package selection, intermodal journey planning, booking, smart ticketing and payment functions so that the entire chain of transport can be managed in this centralised platform (Kamargianni et al 2016). As with the Finnish model MaaS London allows for the provision of mobility packages, which consist of tailored bundles of mobility services customised to individual needs. A commuter package for example would offer a sufficient amount of national rail, London Underground, bus and car sharing services and could be customised to include for example taxi or Uber-like services.

Kamargianni et al (2016) describe how packages provide the heart of the innovation in MaaS-London. As with product bundling in other sectors (e.g. telecommunications), packaging is based on the idea that customers value the grouped bundle more than the set of individual items. As an incentive to the suppliers of transport (and other) services, 
Community Transport meets Mobility as a Service: on the road to a new a flexible future

packages can offer increased marketing channels and per unit sales although at a lower per unit cost. It is expected (though still to be verified at scale) that if packaged correctly MaaS can provide exposure to sustainable modes and an increase in their share of use (Karmargianni et al 2016).

In terms of understanding, a major contribution to the way in which MaaS is conceptualised as the combination of the three Bs - bundles, budgets, and brokers (Hensher 2017). Looking to the content of bundles is a recent area of research, typically using discrete choice theory and estimation to identify willingness to pay. This was presented in its early stages for an experiment undertaken in London (Matyas, M \& Kamargianni M 2017) and for Sydney (Chinh Ho et al 2017). This paper focusses on what underpins the type of bundles which can be offered to clients and non-clients of Community Transport recognising that bundling is a mechanism common within service industries where it is used to stimulate demand (Guiltinan, 1987).

\subsection{What are the key drivers for MaaS?}

The literature suggests the key drivers affecting a successful implementation of MaaS are likely to be:

- Technology as an enabler to the delivery of the MaaS vision (Transport Systems Catapult, 2016).

- Widespread availability of modern digital solutions making the demand and delivery of mobility options possible in time windows which previously would not be possible

- Access to open data (e.g. timetables, real-time location information, user-generated content).

- Provision of interoperable payment systems of transport service providers (e.g., railway operators, taxis, local transport operators, car sharing)

- Regulatory reform. Hensher (2017) argues that if Government were to relax the modal regulatory regime to accommodate mixed-mode opportunities offered by one or more service providers a significant change in the services available to customers is very likely.

Scalability is one of the critical challenges with the MaaS model linked to the 'Uberisation' of mobility. Scalability relates to the quantity of services that might be accommodated by a massive shift away from car ownership and bus use towards individualised or group sharing point-to-point or 'point-via point(s) to point' services by smart bookable (driver or driverless) cars or small buses (Hensher 2017). What is also clear is that attitudes towards mobility are changing and that "altering conditions in society and moving attitudes require a brand-new method to transportation policy that reacts to emerging 21st century imperatives... [which allow for]... transportation alternatives and development patterns that allow them [citizens] to live without dependence on an automobile" (Quadract, 2016). Transport Systems Catapult (2016) note that evidence that MaaS growth requires policy intervention, may be found in the 'narrow' set of features available in current MaaS offerings (e.g. taxi service apps offer some Maas features but do not significantly improve multi-modal journeys).

\subsection{Expected benefits of Maas}

Although the MaaS concept is still very much in its infancy and, as noted above, there is not yet quantifiable evidence on the costs and benefits of MaaS or its influence on travel 
Community Transport meets Mobility as a Service: on the road to a new a flexible future

patterns and behaviour of the end users, proponents have put forwarded a number of expected benefits.

Hietanen (2014) classifies the expected benefits of MaaS as:

- User-benefits: personalised, smart mobility services reflecting the users' diverse needs; seamless, well-functioning transport services and easy access to mobility.

- Benefits for public sector: improved effectiveness of the whole transport system; efficient allocation of resources (based on real needs of end-users); growth in employment and vitality generated by new businesses; and improved traffic incident management and a more reliable transport system.

- Benefits for businesses: profitable markets for new transport services; renewed opportunities for the traditional transport and infrastructure business sectors as part of innovative service concepts and co-operation; and smarter transport connections for all sectors.

Transport Systems Catapult (2016) suggest that there are two core strengths to the MaaS business model which will help to unlock the expected benefits, namely: "servitisation" (the MaaS provider creates a value proposition by bundling mobility services) and data sharing, where the Maas provider shares data on the mobility needs of customers to enable transport operators to improve their service.

\section{$2.4 \quad$ Research Motivations}

Hensher (2017) notes that the majority of the literature on MaaS appears to focus on a changing role for the car (and this is not surprising since the MaaS model seems to be very dependent on a revised role for the car) with the expectation that the car will become a (eventually autonomous) vehicle that is used but not owned, available to be booked on demand for a point-to-point trip. However, it is important not to ignore the crucial role of public transport (both fixed route and flexible) in the delivery of MaaS. This paper is part of an investigation to explore how public transport, and especially Community Transport (CT), can contribute towards the delivery of Maas with a focus on a market segment with very specific needs for tailored mobility solutions.

Additionally, Maas may provide an attractive and convenient solution to help meet the mobility needs of those groups who either no longer want to own a car, cannot afford a car or who cannot drive a car. To date, the MaaS concept has been largely driven by societal and technological change amongst the younger generation. Within this, is the idea that younger people are less inclined to purchase a car than those in previous generations, are more open to the idea of sharing a car and like to buy services managed via their mobile device through subscriptions (an analogy with the bundling of telecom services is often made). How MaaS can be applied to older people (aged over 65) given none of these characteristics generally apply to them leads to the question of how might MaaS offer a future direction for Community Transport (CT) and forms the motivation for this paper.

MaaS is likely to change the bus passenger mix through the offering of a wider mix of collective transport options. This paper considers the CT context in Australia, specifically New South Wales (NSW) as a MaaS market. This is an opportune moment for such an investigation since the funding of $\mathrm{CT}$ is set to change providing a necessity for $\mathrm{CT}$ operators to reassess the way in which their services are provided. Perhaps more importantly, CT operators currently provide their services in an environment where the private car is rarely 
Community Transport meets Mobility as a Service: on the road to a new a flexible future

owned and so MaaS becomes a question of whether a wider range of mobility services can be offered than simply those provided by the CT operator.

CT operators are perhaps the best-known providers of flexible transport services (now defined by the NSW government as point to point services) of course also operated by taxis and increasingly Uber-like and lift-share organisations. These have existed for many years but had a leap forward in development when technology was able to assist (Mulley and Nelson 2016). It seems that these point-to-point operators are at the heart of being able to provide the tailored but packaged mobility of MaaS with the add-ons of other mobility services alongside.

\section{Method}

\subsection{Context}

The institutional framework for Community Transport (CT) in Australia has developed in different ways in different States. In general there is no accepted definition but defining CT as not-for-profit, being based on community need and consisting of targeted and flexible services would cover the type of service provided in each State.

Nationally, until July 2015, funding for CT came from the Home and Community Care (HACC) program which was a nationwide scheme administered via the States and Territories. HACC was provided by the Commonwealth to the States and Territories by means of a block grant which was then provided to service providers. Service providers, upon signing the funding agreement were awarded funds, usually in the form of a block grant and in NSW, service providers are generally funded for direct transport services.

Funding has been provided for external services defined by passengers e.g. attending a medical appointment or a shopping trip or internal services such as travel to activities run by the CT's own organisation, e.g. day care. In 2013 this was estimated as $\$ 113,000,000$ for the HACC program by a National Review and over $\$ 250 \mathrm{~m}$ when non-transport elements of the HACC program were included (Verso Consulting 2014, p.11).

1 July 2015 brought a change with a replacement of the HACC program by the Commonwealth Home Support Program (CHSP) although for CT this will not have an impact until mid-2018. The rationale underpinning the changes is to provide individualised funding through providing funding via the client rather than by block funding to service providers.

Concern in the CT sector over these changes stems from the way in which current funding, provided as block funding, allows client contributions to services to be standardised so that, for example, all clients taking a shopping trip on a group basis will pay the same client contribution (this is not a 'fare' as in most cases CT organisations are not legally able to charge a 'fare' nor are they able to insist upon a contribution). However, this means that client contributions are rarely related to the costs of the service since high cost clients who require significant additional care to undertake the journey or who are wheelchair-bound requiring a more expensive vehicle because of the wheelchair access or who are slow to walk requiring the bus to have a longer dwell time, pay the same as low cost clients. Inevitably, there is a degree of cross subsidisation between the activities of a CT organisation.

In the future, CHSP clients will receive an annual sum of funding for all their needs. They will need to allocate these funds between transport and other activities. It is possible indeed likely - that an individual will try to source their mobility needs, as with their other needs, as economically as possible. Moreover, the current contributions from clients rarely 
Community Transport meets Mobility as a Service: on the road to a new a flexible future

cover the 15 per cent the Commonwealth has signalled they want from CT provision. Overall, this will not be good news for CT operators who may find that they become the providers only of the high cost services since their services, when offered at a 'price' reflecting the unsubsidised cost will appear expensive.

The transfer of funds to the consumer moreover sends a signal that mobility needs are to be made in a more market orientated framework given that CT organisations will need to compete for customer bookings. This requires a paradigm shift for CT organisations who are established parts of the welfare system. Moreover, in the future, the customer base will be receiving funds as part of a welfare package to cover all their need rather than separating out transport as an enabling service requiring separate funds. Consequently there is a mismatch between the signalling of funding which is welfare based and the future of provision of mobility services which seems destined to be in a more contestable market than at present.

One solution, and the solution addressed by this paper, is for CT organisations to become mobility providers for their existing client group and for other citizens requiring mobility services. In this scenario, CT operators provide a range of mobility packages for sale in much the same way as telecom providers provide a range of products covering phone, text and data. Customers for mobility packages choose the package most suited to their needs in exactly the same way a customer for a telecom package chooses the package of phone, text and data that best reflects their anticipated telecom needs. Selling packages of mobility in this way clearly comes under the heading of Mobility as a Service (MaaS).

\subsection{Research design and data collection}

CT providers vary significantly in terms of their opportunities and appetite for entrepreneurial activity. Currently registered as 'not for profit' organisations, some CT operators are moving towards social entrepreneurship as a business model for the future whilst still relying on the current block funding model.

To ascertain whether any CT organisations may have an appetite to become mobility providers, the study approached a small number of organisations in this very specialised market segment. In NSW and Queensland, the block grant received by CT organisations effectively provides a subsidy per trip for a specified number of trips to their client group of older and frail people, people with disabilities and, in some cases, people suffering from transport disadvantage. This research was motivated by wanting to understand the willingness or otherwise of CT operators to consider bundling services, as with MaaS, as a way of continuing to meet the needs of their clients in a potentially new funding regime.

In seeking to understand the willingness of CT organisations to bundle their services, five of the more entrepreneurial CT operators covering urban, suburban and outer suburban operations in NSW and multiple areas in Queensland were approached. Their service characteristics are summarised in Table 1 and shows a broad cross section of operators in this specialised market. A list of questions was prepared to enable a semi-structured conversation with each operator, initially by telephone. The CEO of the organisation was the contact point for the telephone interview which lasted approximately an hour. The individual conversations were followed by a discussion type meeting where all CEOs came together, with the exception of the CEO based in Queensland who joined by conference call. The first round of individual conversations served to unpack the type of operation undertaken, the second round where all CEOs met together to discuss, approximates a focus type meeting without the usual incentives required for attendance. 
Community Transport meets Mobility as a Service: on the road to a new a flexible future

To introduce the concept of MaaS and the type of package that might be offered, the CEOs were sent three vignettes to illustrate possible scenarios (for both existing and new clients). The three vignettes were developed with knowledge of the existing range of CT services and an understanding of their range of clients. They were created to be relevant and to promote discussion and were effective in this aim. Unit costs were determined from publicly available data and in consultation with CT operators. These were as follows:

\section{Example 1: Existing client}

Nora is 79 years of age and lives independently with her 78 year old husband Stan who is at the early stages of developing dementia. Her family live in a regional town over $120 \mathrm{kms}$ away. Nora and her family would like some certainty for Nora for "how do I get there?" over the next year as her life changes. A monthly package of services that could be offered to Nora could be (where Package B might be more expensive as booked nearer to the time of demand):

\section{Package A: all booked one week or more in advance}

- 2 x $10 \mathrm{~km}$ individual shopping

- $4 \times 10 \mathrm{~km}$ group transport trips to dementia care for Stan

- $4 \times 10 \mathrm{~km}$ medical appointment trips, including podiatrist, GP or specialist etc

- 3 days public transport trips (no advance booking required)

- $2 \times 120 \mathrm{~km}$ trip to visit family by public transport with access by taxi to get to and from public transport (this is one return trip)

- $10 \mathrm{~km}$ day time taxi trips in total

Package B:

- Booked one day in advance

- $4 \times 10 \mathrm{~km}$ individual shopping

- $20 \mathrm{~km}$ taxi trips

- $2 \times 10 \mathrm{~km}$ medical appointment trips, including podiatrist, GP or specialist etc

- Booked one week in advance

- 4 x 10km group transport trips to dementia care for Stan

- $2 \times 10 \mathrm{~km}$ medical appointment trips, including podiatrist, GP or specialist etc

- 4days public transport trips (no advance booking required)

\section{Example 2: $\quad$ Stroke victim}

Bill had a mild stroke when he was 59 . He is now unable to drive and needs to take intensive therapy sessions on a daily basis for almost three months. His wife Carol cannot drive. Because Bill loved driving he had until this point taken care of all of his and Carol's mobility needs. Neither of them knew anything much about public transport. They live in a suburban area where public transport can be accessed however Carol is unable to carry shopping due to her recurring shoulder injury. As Bill begins improving, all his mobility sessions are provided indoors and Bill can walk independently indoors but has no idea how 
Community Transport meets Mobility as a Service: on the road to a new a flexible future

he will go outdoors and both he and Carol are not confident. They are becoming increasingly isolated. Monthly packages each for Bill and Carol could be:

- $4 \times 10 \mathrm{~km}$ Group shopping trips

- $100 \mathrm{~km}$ Social outing trips

- $4 \times 10 \mathrm{~km}$ medical appointment trips, including podiatrist, GP or specialist etc

- 4 days public transport travel

- $30 \mathrm{~km}$ Uber trips for out of hours socialising trips

An add-on package for Bill could provide travel training including travelling on and off buses, road crossing practice, and even as time progresses driving lessons. Bill might also need to separately negotiate a daily top up to his package to go to rehab for 3 months.

\section{Example 3: $\quad$ New Client based on giving up car ownership}

Peter is an active 70 year old. His car has recently been costing him too much for the amount of use and he is not that keen on driving now as his eyesight is poor, especially at night. Peter wants to consider ways to get about without owning a car yet remaining as social as possible. His mother is ninety and in a nursing home which is $40 \mathrm{kms}$ away and not on a direct public transport route. Peter has six grandchildren living all over the place (some in other States of Australia) and he wants to be able to visit them as often as practicable. He also has shopping and appointments of his own to organise and he loves going into the city to art galleries and other outings. A monthly package might be:

- $10 \mathrm{~km}$ individual shopping

- 25 km group shopping

- 8 hours Go-Get (car sharing)

- $10 \mathrm{~km}$ ride share

- 4 days public transport

- $25 \mathrm{~km}$ taxi

- $100 \mathrm{~km}$ group outing

In addition to these vignettes, the CEOs were also sent the outline questions by e-mail to allow for some preparation for the conversation. The topics covered are summarised in Table 1 and the findings are discussed in more detail in the next section.

\section{Individual conversations with CT operators}

\subsection{Types of service offered:}

The CT providers interviewed varied in size with vehicle fleets from 20 to 50 vehicles, paid staff ranging from 20 to 120 and volunteer numbers from 30 to 300 . The number of trips per annum was between 58,000 and 260,000. Similar services were offered by each of the organisations, however the largest one offered mobility co-ordination in addition to transport only services.

Size appeared to bestow several benefits. The largest organisation had the capacity to purchase software, which enabled a deeper understanding of service costs. The effect of recruiting a more entrepreneurially-focused CEO was evident too across all organisations interviewed. The CEOs had typically served in the organisations for over ten years, and in 
Community Transport meets Mobility as a Service: on the road to a new a flexible future

one case 30 years. The NSW groups had a tendency to be constrained by the history of block funding and provider subsidy for a distinctive client group.

\subsection{Partnerships}

All interviewees recognised the provision of social services had profoundly changed and was still changing. Survival was dependent on moving, willingly or otherwise, into a competitive environment. They all acknowledged forming partnerships was integral to this. The smaller organisations had partnerships with their largest not for profit supporter - their local Council. In general Council support provided for garaging vehicles, service promotion and managing parking exceptions to enable appropriate access, especially for medical precincts. Most of the NSW organisations indicated an unknown future in terms of their relationship with local Councils as local government amalgamations are taking place.

There was little evidence of collaboration with any for profit organisations for joint ventures. Indeed one organisation stated that they needed a much bigger and more robust representative body who could do this on their behalf. As small groups in local districts some organisations felt they have limited capacity to negotiate large industry wide negotiations which could benefit a CT provider. The largest organisation had a broader outlook in this respect.

Some organisations have partnerships with taxi companies in their area but this depended on the company and the quality of service offered. Good partnerships with the taxi sector developed from understanding how the cost of using taxis can at different times be cheaper than providing the service themselves.

The largest organisation with its mobility management approach appeared to have the most extensive range and experience in working with partners. This organisation also includes the client as part of their concept of partnership but provides services other than simply transport services.

\subsection{Trends in service growth}

Repositioning of the CT sector has to date occurred in a non-competitive environment. All interviewees reported service growth; from proactive marketing, from increased demand, some from pressure to increase the supply of CT through Government imposing more exacting performance standards. Some CT organisations are still trying to meet newly specified contract KPI's, which they believe have been arbitrarily set. The CEOs of all organisations reported increases in demand for medical and social transport services.

Across all services there was an indication that the demand for more individualised services was increasing. One organisation felt that as more and more families are swallowed up by work commitments, the one-on-one travel previously provided by families and their extended networks, especially for medical services was now being sought from CT.

CT operators typically use smaller buses and this fits with the client group who prefer to go in smaller vehicles (e.g. 10 seater). Smaller vehicles are also easier for the client group to manage both for travel time but also for meeting and socializing. It was pointed out that it is easier to get to know others in the smaller group setting, which is something positive associated with the outings offered by the CT organisations. 
Community Transport meets Mobility as a Service: on the road to a new a flexible future

\section{Table 1: Summary of findings from the semi-structured conversations}

\begin{tabular}{|c|c|c|c|c|c|}
\hline Topic & СТ1 & СТ2 & СТ3 & СТ4 & СT5 \\
\hline $\begin{array}{l}\text { SERVICE } \\
\text { CHARACTERISTICS }\end{array}$ & Outer Suburban & Suburban & Inner city & Outer Suburban & Mixed \\
\hline TRIPS & 75,000 & 58,000 & 72,000 & 100,000 & 260,000 \\
\hline STAFF & $\begin{array}{c}26 \text { paid } \\
130 \text { volunteers }\end{array}$ & $\begin{array}{l}20 \text { FT paid } \\
100 \text { volunteers }\end{array}$ & 77 paid & $\begin{array}{l}14 \text { paid drivers } \\
25 \text { casual drivers } \\
\text { oninn }\end{array}$ & $\begin{array}{c}120 \text { staff } \\
300 \text { volunteers }\end{array}$ \\
\hline VEHICLES & 25 & 20 & 27 & 29 & 50 \\
\hline PARTNERSHIPS & $\begin{array}{l}\text { Brokerage of vehicle scheme } \\
\text { No taxis } \\
\text { No Uber }\end{array}$ & $\begin{array}{l}\text { Council } \\
\text { Community Service } \\
\text { Providers } \\
\text { Private hospital } \\
\text { Taxis } \\
\text { No Uber }\end{array}$ & $\begin{array}{l}\text { Council for garaging } \\
\text { vehicles }\end{array}$ & $\begin{array}{l}\text { Two out of } \\
\text { five Councils } \\
\text { One taxi } \\
\text { company } \\
\text { No Uber }\end{array}$ & $\begin{array}{l}\text { Everyone and } \\
\text { Anyone } \\
\text { Engaged in } \\
\text { mobility } \\
\text { management" }\end{array}$ \\
\hline GROWTH TRENDS & $\begin{array}{l}\text { Medical trips } \\
\text { Client assessments } \\
\text { Cancellation growth }\end{array}$ & $\begin{array}{l}\text { Medical and social } \\
\text { trips increases. } \\
\text { Decline in shopping has } \\
\text { dropped }\end{array}$ & Multi-cultural client increases & $\begin{array}{l}\text { On-going growth } \\
\text { Intake } \\
\text { assessments are a } \\
\text { big concern }\end{array}$ & $\begin{array}{l}\text { Big growth } 50 \% \text { per year } \\
\text { "not saying no" mentality. } \\
\text { Looking for other means, } \\
\text { not funding reliant, to } \\
\text { achieve trips. }\end{array}$ \\
\hline $\begin{array}{l}\text { APPROACH TO } \\
\text { RATIONING SERVICES }\end{array}$ & $\begin{array}{l}\text { Out of Area (usually long- } \\
\text { distance) }\end{array}$ & $\begin{array}{l}\text { Out of Area } \\
\text { Manage expectations }\end{array}$ & $\begin{array}{l}\text { No rationing, need to } \\
\text { increase trips to meet KPI's }\end{array}$ & $\begin{array}{l}\text { No rationing; do our best } \\
\text { to meet all requests }\end{array}$ & $\begin{array}{l}\text { Never turn anyone away, } \\
\text { there is a solution for } \\
\text { everything }\end{array}$ \\
\hline BUSINESS PLANNING & $\begin{array}{l}\text { No business plan. Need block } \\
\text { funding }\end{array}$ & $\begin{array}{l}\text { Looking at business models - } \\
\text { partway there but a lot to do } \\
\text { Registered National } \\
\text { Disability Insurance Scheme } \\
\text { (NDIS) provider } \\
\text { A lot of uncertainty but also } \\
\text { know a lot } \\
\text { RouteMatch software should } \\
\text { help }\end{array}$ & $\begin{array}{l}\text { No business plan } \\
\text { Strategic intent to move } \\
\text { forward. } \\
\text { Worried about } 2018 \text {. } \\
\text { Know what to do with block } \\
\text { grants but outside of that } \\
\text { have limited experience }\end{array}$ & $\begin{array}{l}\text { Too much growth, } \\
\text { no real time to } \\
\text { plan. Too many } \\
\text { changes. } \\
\text { Need support and } \\
\text { help to move to } \\
\text { business models }\end{array}$ & $\begin{array}{l}\text { Yes, intend to grow } \\
\text { geographically. } \\
\text { Intimate knowledge } \\
\text { of costs, helps to } \\
\text { obtain sustainable } \\
\text { contracts. } \\
\text { Has a plan to } \\
\text { transition from } \\
\text { block funding } \\
2018 \text {; too early } \\
\text { for full transition. }\end{array}$ \\
\hline
\end{tabular}


Community Transport meets Mobility as a Service: on the road to a new a flexible future

\begin{tabular}{|c|c|c|c|c|c|}
\hline Topic & CT1 & CT2 & СТ3 & СТ4 & CT5 \\
\hline SURVIVAL & $\begin{array}{l}\text { Not confident at all } \\
\text { Need to be larger } \\
\text { Co-operative seen as } \\
\text { the way forward but } \\
\text { not supported by } \\
\text { Government. }\end{array}$ & $\begin{array}{l}\text { Need to work out } \\
\text { how much people } \\
\text { are willing to pay. } \\
\text { May need to pull } \\
\text { back and become } \\
\text { more volunteer type } \\
\text { service } \\
\text { Need a bigger } \\
\text { proactive body who } \\
\text { can negotiate large } \\
\text { block grants }\end{array}$ & $\begin{array}{l}\text { Not very } \\
\text { confident. } \\
\text { May need to } \\
\text { downsize. } \\
\text { Starting to find } \\
\text { out more detail } \\
\text { on costs. } \\
\text { Needs a business } \\
\text { development } \\
\text { officer }\end{array}$ & $\begin{array}{l}\text { Excited about packages } \\
\text { but doesn't know how to } \\
\text { write up new directions } \\
\text { into a business plan. } \\
\text { Client base needs } \\
\text { preparation as they have } \\
\text { not really had any pricing } \\
\text { signals over time. } \\
\text { Concession funding } \\
\text { would be a major } \\
\text { help }\end{array}$ & $\begin{array}{l}\text { In a good position. } \\
\text { Not too small and not } \\
\text { too big. } \\
\text { The different nature } \\
\text { of delivery of } \\
\text { 'mobility' already } \\
\text { packaged with other } \\
\text { types of services is } \\
\text { working for them and } \\
\text { gives them a good } \\
\text { start. } \\
\text { Transport is only } 48 \% \\
\text { of the work they do. }\end{array}$ \\
\hline SERVICE PACKAGES & $\begin{array}{l}\text { Packages will depend } \\
\text { on what family } \\
\text { resources they have } \\
\text { (e.g. own car, own } \\
\text { driver, on demand) } \\
\text { Some just want } \\
\text { the social } \\
\text { contact }\end{array}$ & $\begin{array}{l}\text { Some current clients are } \\
\text { not confident with } \\
\text { technology. } \\
\text { Medical, } \\
\text { Social } \\
\text { Shopping }\end{array}$ & $\begin{array}{l}\text { Medical, } \\
\text { Social } \\
\text { Shopping }\end{array}$ & $\begin{array}{l}\text { Social and shopping } \\
\text { packages } \\
\text { Local and medical }\end{array}$ & $\begin{array}{l}\text { Packages need to be } \\
\text { developed region by } \\
\text { region. }\end{array}$ \\
\hline
\end{tabular}


Community Transport meets Mobility as a Service: on the road to a new a flexible future

Most conversations identified notice cancellations by clients was a problem. The introduction of a cancellation fee was seen as a means to educate clients and to provide a price signal but was also seen as an avenue of conflict and increased administration.

\subsubsection{Rationing services}

All organisations identified no need to ration services. However one organisation said they did actively manage client's expectations. Two organisations indicated that where long distances are involved, some rationing could occur so if three people needed a service on the same day as one person needed a long distance service, the tendency would be to provide for the three shorter trips if there is a constraint. This suggests out of area transport is marginally more difficult for those CT services who operate in areas where major medical and specialist providers are necessarily more distant.

\subsubsection{Business Planning}

Many of the organisations indicated that the uncertain and often changing contract/funding environment hinders high level business planning. This uncertain environment has persisted for the last five years with increasing tension as the time for the removal of block funding in 2018 approaches. There was overall agreement in all conversations that the CT block funded industry is not yet ready for a full transition of funding to individualised client holders by 2018 , although one CEO maintained that despite uncertainty there was enough known to embark on some robust business planning.

For one organisation, headed by a CEO with a thirty year history, the requirement to move to a 'market' place environment provided a personal stress since their motivation arises from the belief that the assets and social capital of most value to the organisation are being pushed into the background by the new competitive environment. Another organisation indicated they had strategic plans to move ahead but admitted that there is no business plan to move the fuzzy concepts of the strategic plan into something that operationalises the way forward. Another CEO identified how the many 'efficiency' changes that arrived with contracts had left little or no time for changing models of service from welfare to the market place (i.e. moving from producer subsidy to consumer subsidy). One organisation noted the asymmetry between the CT and taxi industry with the commercial taxi industry being supported by capacity building funds to allow transition to be competitive with the arrival of Uber and similar developments.

The largest organisation interviewed, despite any misgivings on the state of play in the industry, was well advanced with a business plan for optimizing objectives under several constraint scenarios. Due to the size of the organisation it had a capacity to think in terms of spreading geographical reach and fast operationalisation of service contracts, while not being too fixed on the guidelines but rather on delivery of services for the greatest number of clients.

\subsubsection{Survival}

There were mixed views about survival. The largest organisation was confident. The organisations divided between seeing that opportunities do exist for growth or they would end up focusing on a smaller niche market. Size for survival was an issue with some differences in view as to the necessary size for survival. While many of the CT organisations felt that they can perform better than any of the alternatives (such as taxis and Uber), they 
Community Transport meets Mobility as a Service: on the road to a new a flexible future

were not necessarily confident in acquiring new contracts: the prevailing view was that they wanted a larger organisation to work with them on such ventures.

\subsubsection{Service packages}

All interviewees supported the 'idea' of service packages. While they could see that the notion of packages would contribute to their resilience, they were less able (at this point) to see how packages could make their organisation distinctive. In the past it must be remembered that CT organisations have built a reputation and attracted funds based on the "distinctiveness" of what they had to offer (not only transport but a care element) and because it differed so markedly from other transport service offerings. All the organisations interviewed said they would like to know more about the markets outside their current service provision. They also said they would like to know more about clients' willingness to pay for certain packages.

\section{The Discussion meeting with $\mathrm{CT}$ operators}

The Discussion meeting was set up in a structured manner. Following a scene-setting piece outlining the current challenges facing the CT sector, each of the 5 participating operators were encouraged to outline their aspirations for the future in a roundtable discussion. This inevitably covered many of the topics raised in the individual conversations and discussed above. Following this the whole group worked together to complete a practical exercise of "package building".

\subsection{Aspirations and challenges}

In a wide-ranging discussion participants identified a number of issues.

All operators agreed that there are challenges that will shape the future of their organisations. One urban operator put it starkly by stating the need to find a new business model in the next 18 months.

In terms of software applications the NSW operators noted that the use of a particular software package (RouteMatch) was being imposed on them and being paid for by the government. It was noted that this could provide opportunities to work together with the developers and the formation of a user group was recommended.

The concept of packages was viewed favourably. It was noted that these could be viewed as similar to existing transport and welfare service offerings where the client made a decision as to how to spend a total amount on the services they require. One potential advantage would be to spread costs and make the more expensive individual journeys less visible through bundling with the less expensive social outings.

There was cautious optimism about the use of other modes as part of service delivery (e.g. liftsharing, car clubs, Uber etc) although it was noted that clients require a certain level of care. The outer suburban operator pointed out the relative paucity of such possibilities in their operating area, although in a later part of the discussion it was agreed that in many rural contexts first/last mile issues can be addressed by flexible transport services.

It was recognised that there should be future opportunities for CT operators to make better use of their own mobility resources. One operator pointed out that their own experiences over many years meant that they were already well versed with the concept of 
Community Transport meets Mobility as a Service: on the road to a new a flexible future

private car services. One might imagine a future scenario where CT car drivers switch to becoming Uber or other 'app' based drivers in their downtime or 'after hours'.

The future nature of the client base was also discussed. It is anticipated that MaaS packages will provide certainty to both operators and clients but it was suggested by a medium-sized operator that perhaps everyone should be viewed as a potential client in future and that the distinction between client and non-client would become less important.

\subsection{The service packages exercise}

Participants were presented with cards which provided possible components of potential bundles. These included: liftshare, public transport, individual travel, group travel, Uber trips, car share and taxi. Each of the modes were available as a costed unit comprising a distance and cost component. The cost of the trip was calculated by reference to published charges for non-CT modes and by reference to modelled CT costs for CT operations.

Participants were presented with "pen portraits" of potential users and asked to allocate potential packages of services. Table 2 shows two examples.

Table 2: Pen portraits of potential clients and associated packages

\begin{tabular}{|l|l|c|}
\hline & Potential package per month & Cost (\$AUD) \\
\hline Case 1: Female, urban dweller & $1 * 100 \mathrm{~km}$ each way group travel & 85 \\
75 years old, husband died & $2 * 10 \mathrm{~km}$ each way group travel (shopping) & 114 \\
recently, Non-driver, Hospital & $2 * 20 \mathrm{~km}$ each way group travel (social) & 10 \\
$\begin{array}{l}\text { appointment every } 6 \text { weeks. } \\
\text { Family around but not very }\end{array}$ & $1 * 10 \mathrm{~km}$ each way Individual transport (hospital) & 100 \\
available & $4 * 10 \mathrm{~km}$ taxi & 10 \\
\hline Case 2: Male, urban dweller & $4 * 40 \mathrm{~km}$ GoGet car sharing & 140 \\
Just turned 65, No car but likes & $10 * 5 \mathrm{~km}$ taxi & 20 \\
driving, & $8 *$ public transport (2/week) & 125 \\
Grandchildren nearby. Weekly & &
\end{tabular}

These pen portraits and associated packages raised the issue of how to present to clients and future users. Currently, clients are subsidised for each trip and until block funding is removed, subsidy can be deducted from each package for eligible users. For case 1 the full cost package would be $\$ 473$. But taking into account the per trip subsidy of $\$ 31$ per trip and the current co-payments by clients (estimated at the level of the lowest cost provider) the cost of the package would need to be $\$ 103$ per month, against current payments of $\$ 88$. Of course, when the subsidy is in the hands of the client or for those not eligible for subsidy, the 
Community Transport meets Mobility as a Service: on the road to a new a flexible future

cost of the package 1 would be $\$ 473$ with the subsidy needing to come from their annual payments. For those eligible for subsidy the package would under current conditions be only $\$ 15$ more than current payments by clients, but when funding is transferred to the client such a package is likely to be perceived as expensive with potential affordability being dependent on the full per trip subsidy being placed in the hands of the client. This process was repeated for Case 2, although it is more likely that someone with a Case 2 profile would not be eligible for subsidy, especially if younger than 65.

A number of points emerged from the discussion, particularly in relation to types of travel not presented for inclusion in the packages. The theme of "build your own" packages emerged very strongly although it was recognised that it was important to have standard packages rather than customised ones. Offering service packages was also seen as a way of encouraging more activity, especially social outings which could increase inclusion. An idea that gained approval was to have a package creation that allowed selection of different items from a list so that purchasers felt they had some customisation. It was felt that offering other items as part of the package, perhaps as an "add-on" would be important and suggestions for these included: household travel planning; car next door information and help; travel training; ICT training; providing a driver for own car; learning to drive. Alternatives to a client having to sell their car might be passing the ownership to the CT organisation in return for an agreed amount of service in return over a given period (e.g. via the "car next door" scheme).

\section{Conclusions}

This paper has sought to explore the contribution of public transport, as characterized by the Community Transport (CT) sector, in the development and delivery of Mobility as a Service (MaaS). The opportunity to consider new mobility options follows a changing of the funding landscape and an increasing amount of funding proposed to be in the hands of the customer or client.

Following a review of relevant literature the paper has described the outcome of a study with five Australian CT operators whose clients represent a market segment with very specific needs for tailored mobility solutions. A semi-structured conversation followed by a discussion type meeting brought CEOs together to explore the concept of MaaS and the types of package that might be offered.

The findings indicate a strong enthusiasm amongst CT operators for offering packages of mobility services to their current users and to investigate delivery of packages to nonusers/new users. The opportunity to 'lock in' customers to an organisation was seen as a clear benefit of the packages since a considerable fear, and likely otherwise reality, is for CT operators to be left with the provision only of expensive to provide trips.

A clear theme to emerge is the way transport for the aged and people with disabilities are still being treated as a welfare issue in Australia. The MasS approach offers the possibility to take mobility to another level where transport or mobility is not simply regarded as entitlement (under threat by Government cuts) but an essential part of engaging in society. However, whilst the paradigm shift is understood and recognised by CT operators, being more entrepreneurial and expanding the client base, will only ever be of limited success until the full social benefit of mobility services is recognised. For those CT operators willing to step outside of their traditional means of service delivery, the Maas packages 
Community Transport meets Mobility as a Service: on the road to a new a flexible future

proposed in this paper provide an opportunity to start the process of valuing the benefit of access, through the provision of transport to persons with disabilities or aged and frail. Within such a model, they would offer journey planning to find transport possibilities and a subscription service for payments which would allow older passengers to work with the CT organisation to choose the mobility bundle which best meets their needs.

Future research needs to consider how the packages should be formed, what elements are provided for existing clients and also for current non users. This is proposed to follow using a stated preference choice experiment to identify the attributes that customers are willing to pay for.

\section{References}

European Commission (2016) Smart, Green and Integrated Transport Work Programme. Hensher DA (2017) Future bus transport contracts under a mobility as a service (MaaS) regime in the digital age: Are they likely to change?, Transportation Research Part A: Policy and Practice, vol.98, pp. 86-96

Guiltinan, JP (1987) The price bundling of services: A normative framework', The Journal of Marketing, pp. 74-85.

Hietanen, S (2014) 'Mobility as a Service' - the new transport model? Eurotransport, 12 (2), 2-4. http://www.itsineurope.com/its10/media/press clippings/ITS\%20Supp et214.pdf . Accessed July $3^{\text {rd }} 2016$

Ho, C., Hensher, DA, Mulley, C and Wong, YZ (2017) Prospects for switching out of conventional transport services to mobility as a service subscription plans - A stated choice study, 15th International Conference on Competition and Ownership of Land Passenger Transport (Thredbo 15), Stockholm, Sweden

Kamargianni, M., Matyas, M., Li, W. and Schäfer, A. (2015) Feasibility Study for "Mobility as a Service" concept in London FS-MaaS Project, UCL Energy Institute, London, May. https://www.bartlett.ucl.ac.uk/energy/docs/fs-maas-compress-final Accessed July $3^{\text {rd }} 2016$

Karlsson, M., Sochor, J., and Strömberg, H. (2016) Developing the 'Service' In Mobility as a Service: Experiences From a Field Trial of An Innovative Travel Brokerage, Transportation Research Procedia, vol. 18-21, pp. 3265-3273.

Matyas, M \& Kamargianni, M (2017) Stated preference design for exploring demand for "mobility as a service" plans, International Conference of Choice Modelling, Cape Town, South Africa.

Mulley C and Nelson J D (Eds) (2016) Paratransit: Shaping the Flexible Transport Future (Transport and Sustainability, Volume 8), Emerald Group Publishing Limited, Bingley, United Kingdom).

Mulley, C (2017) Mobility as a Services (MaaS)-Does it have critical mass?', Transport Reviews, vol. 37, pp. 247-251. 
Community Transport meets Mobility as a Service: on the road to a new a flexible future

Quadract (2016) Reviewing The Peak Car Debate. Posted at:

http://www.quadract.com/reviewing-the-peak-car-debate/

Sochor, J., Karlsson, M., and Strömberg, H. (2016) Trying Out Mobility as a Service Experiences From Field Trial and Implications for Understanding Demand, Transportation Research Record, vol. 2542, pp. 57-64

Sochor, J., Strömberg, H., and Karlsson, M. (2015) Implementing Mobility as a Service Challenges in Integrating User, Commercial, and Societal Perspectives, Transportation Research Record, vol. 2536, pp. 1-9

Transport Systems Catapult (2015) Transport Systems Catapult (2015) Traveller Needs and UK Capability Study. Transport Systems Catapult, October. https://ts.catapult.org.uk/wpcontent/uploads/2016/04/Traveller-Needs-Study.pdf Accessed July $3^{\text {rd }} 2016$

Transport Systems Catapult (2016) Mobility as a Service. Exploring the possibility for Mobility as a Service in the UK. Transport Systems Catapult, July.

https://ts.catapult.org.uk/wp-content/uploads/2016/07/Mobility-as-a-Service Exploring-theOpportunity-for-MaaS-in-the-UK-Web.pdf Accessed Feb 14th 2018

Verso Consulting (2014) National Review of Community Transport Under the Commonwealth HACC Program. 